\title{
Transatlantica
}

Revue d'études américaines. American Studies Journal

\section{New York, Weegee the Famous}

Le Pavillon Populaire, Esplanade Charles de Gaulle, Montpellier, jusqu'au 15 septembre 2008, entrée libre du mardi au dimanche, www.montpellier.fr

\section{Claude Chastagner}

\section{(2) OpenEdition}

Journals

Édition électronique

URL : http://journals.openedition.org/transatlantica/4103

DOI : $10.4000 /$ transatlantica.4103

ISSN : 1765-2766

Éditeur

AFEA

Référence électronique

Claude Chastagner, « New York, Weegee the Famous », Transatlantica [En ligne], 1 | 2008, mis en ligne le 20 août 2008, consulté le 29 avril 2021. URL : http://journals.openedition.org/transatlantica/4103 ; DOI : https://doi.org/10.4000/transatlantica.4103

Ce document a été généré automatiquement le 29 avril 2021.

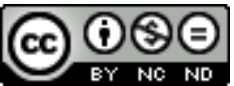

Transatlantica - Revue d'études américaines est mis à disposition selon les termes de la licence Creative Commons Attribution - Pas d'Utilisation Commerciale - Pas de Modification 4.0 International. 


\section{New York, Weegee the Famous}

Le Pavillon Populaire, Esplanade Charles de Gaulle, Montpellier, jusqu'au 15 septembre 2008, entrée libre du mardi au dimanche, www.montpellier.fr

\section{Claude Chastagner}

1 «Weegee the famous » : le surnom dont s'est affublé Arthur H. Fellig évoque plus, dans sa vantardise ironique, le bonimenteur de cirque, le carnival barker, que le photographe de talent. Rien non plus dans son allure physique qui incite à l'inclure dans le cercle fermé des "vrais " artistes, des grands photographes américains célébrés par les magazines et les rétrospectives, comme Ansel Adams ou Walker Evans, même si lui aussi a eu les honneurs d'Hollywood, de Vogue et du MOMA. Avec ses complets mal ajustés, ses cigares bon marché et son encombrant embonpoint, Weegee ressemble avant tout à son sujet de prédilection, l'Amérique des humbles, des déshérités, l'Amérique du quotidien et du dérisoire.

2 Américain, Weegee l'est aussi par son parcours, parfois chaotique d'un émigré ordinaire, fils de rabbin austro-hongrois, parcours qui est aussi l'incarnation presque parfaite du rêve transatlantique, dans son sublime et son pathétique. La vie de Weegee est une success story exemplaire, sur le modèle from rags to riches dont Hollywood est si friand, qui l'a amené à la gloire et à la fortune, et l'a fait côtoyer les démunis comme les nantis, les anonymes comme les stars. Le regard plein d'humanité et de férocité que Weegee a jeté sur ses contemporains est présenté, après le musée Maillol l'an dernier, au Pavillon Populaire de Montpellier jusqu'au 15 septembre. Son directeur artistique, Roland Laboye, a obtenu que soit exposée à Montpellier une partie de la collection Michèle et Michel Auer, 281 tirages originaux de grand format, allant des années trente aux années soixante, du célébrissime Coney Island (1940) au plus confidentiel Heatspell, May 23, 1941.

3 On peut regretter, malgré son exiguïté, l'ancienne galerie de la photographie de Montpellier pour ses éclairages délicats et la géométrie simple et élégante de ses volumes. On ne peut en revanche que se réjouir qu'une ville comme Montpellier se soit dotée d'un bâtiment dédié à la photographie, en plein cœur de ville, à deux pas du nouveau musée Fabre, sur une Esplanade malencontreusement enlaidie cette année par 
de vilaines baraques en bois consacrées " aux produits locaux ", où l'humble passant est invité, sur l'inévitable et exécrable fond musical, à se délester de ses derniers euros.

Malgré ce couac municipal regrettable et l'horrible bandeau jaune agressif qui accueille le visiteur, l'exposition Weegee s'impose comme une des plus belles d'une déjà longue et riche série. Dans le vaste Pavillon, les commissaires ont choisi un accrochage thématique simple et convaincant. Pour ceux qui ne connaissaient que les tirages médiocres des quotidiens pour lesquels Weegee travaillait, la qualité des clichés exposés sera une révélation. Accompagnée d'excellents cartels explicatifs, l'exposition passe en revue les grands thèmes qui structurent l'œuvre de Weegee: le monde spectacle, du cirque à l'opéra, du strip-tease au cinéma ; la vie nocturne de Harlem ou du Bowerie, quand la misère prend possession de la rue pour y dormir ou y faire la fête ; celui des anonymes saisis en pleine vie et des stars dociles qui posaient pour Weegee; celui enfin, de la violence des hommes, meurtres, accidents, incendies. L'exposition de Montpellier s'attarde aussi sur les autoportraits et les nombreux photomontages et distorsions que Weegee expérimentait avec ses Speeed Graphic, Polaroid ou Hasselblad, grâce à des films infrarouges ou à des objectifs prismatiques. Sont également présentées les éditions originales des livres qu'il a publiés et une amusante mais instructive réplique du coffre arrière de la Chevrolet qui lui servait de laboratoire et de bureau, et où il s'installait pour travailler, à chaud, dans l'urgence.

Difficile de dire si Weegee, au même titre qu'un Frank ou un Friedlander, dénonce la vacuité et le mensonge du rêve américain, s'il se contente de montrer le spectacle de la vie, ou s'il se complait dans le voyeurisme et le misérabilisme. L'exposition de Montpellier révèle avant tout un photographe acharné et assidu, qui se levait souvent à l'aube et travaillait dans une veine réaliste typiquement américaine. On y retrouve le goût pour la narration, pour des sujets humbles et quotidiens et le choix d'un mode de représentation brut, non idéalisé, qui ne répugne pas à une certaine mise en scène, où même les plus célèbres (Barbara Streisand, Andy Warhol, Marilyn Monroe, Christine Keeler, Salvador Dali) dévoilent leurs défauts, où la sauvagerie urbaine à peine policée fait écho à la vulgarité d'une haute société dont les coulisses sont explorées sans aménités.

6 Y a-t-il de la tendresse et de la compassion, de l'ironie et de l'autodérision, dans son regard ? Certainement, mais plus encore, la photographie de Weegee se veut neutre. En refusant, comme Diane Arbus le fera plus tard le sentimentalisme et le romantisme, en privilégiant son autonomie (il ne participe pas aux programmes d'aide financés par le gouvernement), Weegee nous propose de remplir le cadre à notre guise. À ce titre, une des photos les plus emblématiques de Weegee est peut-être Their First Murder (1941). La multitude des angles, des lignes de fuite, des regards y renvoie à la pluralité des lectures possibles. Le cadavre importe peu, ce sont les spectateurs qui comptent. En écho aux réactions complexes, tantôt malsaines, tantôt compassionnelles, que suscite en nous le spectacle de la violence et de la mort, ils jouent avec et pour le photographe. Du tragique à la curiosité, de l'excitation au désespoir, même les enfants ne sont pas épargnés. Pourtant, Weegee est trop fin connaisseur de l'espèce humine pour porter un jugement ou condamner. C'est la rue, la vie telle qu'elle se déroule. Il était là, il a regardé où il fallait. À nous de sonder ces regards pour y retrouver une fascination ambiguë que nous connaissons trop bien. 